\title{
LA TERMINOLOGÍA DEL MAÍZ EN ARAGÓN, NAVARRA Y RIOJA
}

\author{
Maria Pilar Garcés \\ Universidad de Málaga
}

La introducción en España y, posteriormente, en Europa de un nuevo cereal procedente del Nuevo Mundo ${ }^{1}$ ha suscitado el interés de los lingüistas por investigar qué procedimientos utiliza la lengua cuando ha de nominar nuevas realidades ${ }^{2}$. Respecto al área iberorromance ya se han realizado algunos trabajos sobre los nombres españoles del maíz ${ }^{3}$ y acerca de sus designaciones en zonas concretas ${ }^{4}$; dentro del ámbito lingüístico regional es fundamental el análisis que hace el profesor don Manuel Alvar de la terminología del maíz en Andalucía ${ }^{5}$, basándose en las documentaciones que proporcionan cinco mapas de su Atlas Lingüístico ${ }^{6}$; siguiendo por este camino y aprovechando los materiales que se recogen en el Atlas Lingüístico y Etnográfico de Aragón, Navarra y Rioja?, vamos a analizar los términos

\footnotetext{
' A pesar de que las denominaciones que recibió el nuevo cereal en Europa contribuyeron a oscurecer su procedencia al mencionarse distintos lugares como los de origen del maiz, este cereal es indiscutiblemente originario de América; cfr. J. J. Montes Giraldo y M. L. Rodríguez, El maiz en el habla y la cultura popular de Colombia. Bogotá, Instituto Caro y Cuervo, 1975, pp. 20-1.

${ }^{2}$ Cfr. G. Pascu: «Le maïs dans les langues romanes et balkaniques», en Estudis Universitaris Catalans, XXI, 1936, pp. 451-469.

${ }^{3}$ Cfr. P. Garcia Mouton: «Los nombres españoles del maíz», en Anuario de Letras, XXIV, 1986, pp. 121-146.

4 Cfr. M. Menéndez García: «El maíz y su terminología en Asturias», en Homenaje a $F$. Krüger, II. Mendoza, Universidad de Cuyo, 1954, pp. 369-402.

Vid. M. Alvar: «La terminología del maíz en Andalucía», en Mélanges de Linguistique et de Philologie romanes offerts à M. Pierre Gardette. Strasbourg, 1966, pp. 27-38.

${ }^{6}$ vid. M. Alvar: Atlas Lingüístico y Etnográfico de Andalucia (ALEA), con la colaboración de A. Llorente y G. Salvador. Granada, 1961-73, vol. I, mapas 102, 103, 105, 107, 108.

${ }^{7}$ M. Alvar: Atlas Lingüístico y Etnográfico de Aragón, Navarra y Rioja (ALEANR), con la colaboración de A. Llorente, T. Buesa y E. Alvar. Madrid, 1979-83, vol. I, mapas 105-111.
} 
que designán el cereal y cada una de sus partes en este dominio; de este modo, podremos aportar nuevos datos a los estudios ya publicados y señalar las relaciones que se establecen entre los vocablos que aparecen en los distintos dominios peninsulares.

\section{MaÍz}

El vocablo más extendido es panizo y la correspondiente voz catalana panis en los pueblos de la frontera oriental de Huesca, Zaragoza y norte de Teruel.

Panizo es una palabra derivada del latín tardío p a $\mathrm{n} \overline{\mathrm{i}} \mathrm{c} \mathrm{i} \mathrm{u} \mathrm{m}$, que denominaba una vieja gramínea europea, pero al descubrirse América, y tras la importación del nuevo cereal, se hizo extensiva para designar el 'maíz' en diversas partes de España. La amplia difusión que tiene este vocablo en Aragón ha favorecido su propagación por la zona oriental de la Península: panizo 'maiz, planta y grano' se registra en $\mathrm{Murcia}^{8}$, y en puntos del andaluz oriental ${ }^{9}$, donde, según se ha señalado, este mantenimiento estaria favorecido por el influjo levantino y catalán ${ }^{10}$; sin embargo, parece más probable que se trate de una influencia directa del aragonés, donde panizo es casi exclusivo, ya que en catalán sólo se documenta en algunas localidades de la parte occidental ${ }^{11}$.

El nuevo término americano maiz ${ }^{12}$ que es el que se generaliza en la lengua oficial se halla en Navarra y La Rioja; hay que señalar, sin embargo, el género femenino que tiene en $\mathrm{Na} 405,501$ y Lo 103, y el dislocamiento acentual maiz < máiz, que se ha producido en los pueblos navarros y, por extensión, en algunos riojanos (Lo 100, 101, 300, 303, 602), que responde a la tendencia a la diptongación de las vocales en hiato.

Milloca aparece en la zona noroccidental de Huesca; pero en ningún caso es denominación habitual, ya que en $\mathrm{Hu} 102,104$ es palabra poco frecuente y en $\mathrm{Hu} \mathrm{105,} 108$ es voz anticuada. La conservación de este término se debe al influjo gascón, donde este vocablo es general en los de-

8 Vid. J. Garcia Soriano, Vocabulario del dialecto murciano. (ed. facs. de la primera edición, Madrid, 1932). Murcia, Editora Regional, 1980, p. 95.

$\checkmark$ Vid. M. Alvar, ALEA, vol. I, mapa 102.

${ }^{10} \mathrm{Cfr}$. J. Fernández Sevilla, Formas y estructuras en el léxico agricola andaluz. Madrid, CSIC, 1975, p. 113.

"Vid. A. Griera, Atlas Lingüistic de Catalunya (ALC). Barcelona, Institut d'Estudis Catalans, 1923-26, vol. II, mapa 276 (s.v. blat de moro).

${ }^{12}$ Cfr. A. Tovar, "La palabra americana maiz», en Filologia Hispaniensia. Homenaje a M. Alvar. Vol. I. Dialectología. Madrid, Gredos, 1983, pp. 601-8. 
partamentos de Hautes Pyrénées, Basses Pyrénées y Landes (menos en el suroeste) ${ }^{13}$; sin duda, esta forma tuvo una mayor extensión a este lado de la vertiente pirenaica en una época anterior ${ }^{14}$, pero en la actualidad ha quedado relegada a poblaciones marginales y arcaicas como son los lugares en los que se registra.

La forma adaza se halla en el sur de Teruel, motivada por su relación con el catalán dacsa 'maíz' general en tierras valencianas ${ }^{15}$. L. Eguilaz señala dos étimos distintos para cada una de las voces: el vocablo castellano que, según indica, es propio de Aragón, procede del árabe 'ádasa 'arveja' o ‘lenteja', mientras que el catalán deriva de ad-dacsa 'mijo'16. Corominas no cree que sea necesario hacer esta separación, ya que ambas palabras han de proceder de una misma base: el árabe dáqsa 'grano parecido al mijo' ${ }^{17}$.

El sintagma catalán blat de moro que se registra en $\mathrm{Hu} 402$ es una designación compuesta por dos elementos: la forma denotativa blat que ha sufrido un desplazamiento semántico, ya que expresa comúnmente otro cereal $^{18}$, y un determinante que indica su supuesta procedencia, errónea desde el punto de vista histórico.

Los vocablos vascos galdurrua ( $\mathrm{Na} 100)$, caidurrua $(\mathrm{Na} 103)$ aparecen en el norte de Navarra ${ }^{19}$; en ocasiones se hallan juntas la voz normativa maiz y la correspondiente forma vasca artua $(\mathrm{Na} 200,203,204)$ sin ninguna diferencia significativa entre ambas.

\section{FLoR DEL MAÍZ}

Encontramos varias palabras que responden a distintos orígenes semánticos.

Espiga es una denominación metonimica; en algunos casos se considera

13 Vid. J. Séguy, Atlas Linguistique et Etnographique de la Gascogne. Paris, Centre National de la Recherche Scientifique, 1954-66, vol. II, mapa 218.

14 En el dominio lingǘstico catalán se documenta milloc (Valls d'Aneu i de Cardós, Tremp), milloca (Balaguer, Lleida, Pla d'Urgell) con este mismo valor, cfr. A. M." Alcover y F. de B. Moll, Diccionari català-valencià-balear (DCVB). Palma de Mallorca, Moll, 1980, vol. VII, p. 426; vid. además, A. Griera, $A L C$, I1, mapa 276.

is Cfr. J. Corominas, Diccionari etimologic $i$ complementari de la llengua catalana. Barcelona, Curial, 1980 ss., vol. III, pp. 9-10; vid. además, A. Griera, ibid.

16 L. Eguílaz y Yanguas, Glosario etimológico de las palabras de origen oriental (Granada, 1886). Madrid, Atlas, 1974, p. 52.

17 J. Corominas, Diccionario critico etimológico castellano e hispánico (DCECH). Madrid, Gredos, 1980 ss., vol. II, p. 428.

18 Vid. A. Griera, $A$ LC, II, mapa 275 (s.v. blat).

19 Cfr. R. M." de Azkue, Diccionario vasco-español-francés (3." ed. de la de Bilbao, 1905 6). Bilbao, 1984, vol. I, p. 320. 
un término de gran amplitud semántica y se especifica mediante un determinante: espiga del panizo (Z 400), espiga de adaza (Te 502). El derivado espigón se registra predominantemente en Teruel; quizá el empleo de este vocablo se explique porque el hablante siente la necesidad de establecer una distinción léxica entre los significados de 'flor del maíz' (espigón) y 'espiga del trigo' (espiga) a través del sufijo -ón que ha perdido su primitivo valor funcional; el diminutivo espiguilla sólo en Z 500 .

Otra palabra que responde a un proceso metonímico es flor, que se documenta en la zona norte de este ámbito lingüístico.

Punta es una designación metafórica surgida por comparación con el extremo agudo de la flor.

Algunas formas que aparecen de modo esporádico responden a asociaciones metafóricas basadas en semejanzas reales o subjetivas con la realidad designada: capullo, cabeza, corona, coroneta, copa, escoba, escobeta, escobilla, capota, cogote; otras veces se trata de desplazamientos semánticos ocasionales: panolla ( $\mathrm{Hu} \mathrm{112,} \mathrm{Z} \mathrm{303),} \mathrm{panoja} \mathrm{(Z} \mathrm{503),} \mathrm{pinocha} \mathrm{(Te} \mathrm{304).}$

Los términos vascos lorea (Na 102), tontorra (Na 101), artobizarra ( $\mathrm{Na} 100$ ), este último designa habitualmente la 'barba de la mazorca', pero ha ampliado su significado y expresa también este valor ${ }^{20}$.

\section{BARBA DE LA MAZORCA}

La forma más general y extendida para denominar los 'pelos rojizos que coronan la mazorca' es pelo y los derivados pelusa, pelusilla ( $\mathrm{Hu} 302$, Te 103), pelillo (Te 101); su sinónimo cabello sólo se halla en un punto (Te 200); los correspondientes términos catalanes cabell y pell y el derivado cabellera se registran en la frontera oriental de Huesca, Zaragoza y norte de Teruel.

Como pelo es un vocablo de gran extensión semántica, en algunas localidades se especifica a través de diversos determinantes que hacen referencia a la 'mazorca': pelo de pinocha $(\mathrm{Hu} 301, \mathrm{Z} 300,304,402,600)$, pelo de la piña (Z 301, 502, 602, Te 104, 301), pelo panolla (Te 102), pelo de panolla $(\mathrm{Z} 603,605)$, pell de panolla $(\mathrm{Z} 606)$; o bien al 'maíz' en general: pelo de maiz (Na 301, 303, 400, 501, Lo 304, 604), pelo de panicero $(\mathrm{Hu} 101)$. La denominación pelos de vieja (Z 504) surge por la semejanza que existe entre ambas realidades, ya que son finos y están separados.

Por una comparación entre los 'pelos de la mazorca' y la 'seda' surgida

${ }^{20}$ Vid. Azkue, I, 553 (s.v. lore); II, 283 (s.v. tontor); I, 83 (s.v. artobizar). 
a través de los semas comunes 'suavidad' y 'brillo' se halla la forma seda en localidades del norte de Huesca (Hu 109, 200, 203).

Otras denominaciones metafóricas esporádicas: moño (Te 202), araza

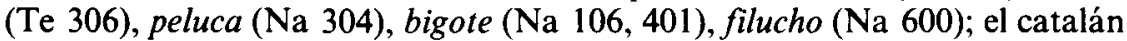
fils (Hu 202) y los vocablos vascos artobizarra ( $\mathrm{Na} \mathrm{100),} \mathrm{pitsarra} \mathrm{(} \mathrm{Na} 101)$, mits̃arra $(\mathrm{Na} \mathrm{104})^{21}$.

\section{FARFOLla}

Hoja es una voz de gran amplitud semántica que se ha especializado ocasionalmente con este valor; en algunas localidades se especifica su significado mediante complementos determinantes: hoja de maiz ( $\mathrm{Na} 306,309$, 500, Lo 303, 601), hoja de panizo (Hu 108, 204, 207), hoja de panicera (Hu 111), hoja de pinocha $(\mathrm{Hu} 206)$. La correspondiente forma catalana fulla aparece en la frontera oriental de Huesca y norte de Teruel.

Por un desplazamiento semántico encontramos pinocha con el sentido de 'farfolla'; en tres casos (Hu 103, Z 303, 504) se ha producido confluencia de significados y esta voz designa 'farfolla' y 'mazorca'; en el resto de los pueblos se establece una distinción léxica entre ambos sentidos, ya que se utilizan voces procedentes de étimos distintos: piña/pinocha $(Z 500,502$, 505), piña/pinorcha (Z 607), panolla/pinocha (Te 200), que expresan 'mazorca' y 'farfolla' respectivamente.

En algunos puntos se emplea un sufijo que ha perdido su primitivo valor y sirve para establecer diferencias significativas entre pinocha 'mazorca' y el derivado pinochera 'farfolla' ( $\mathrm{Hu} \mathrm{303,305,} \mathrm{Z} \mathrm{304,} \mathrm{400).}$

Pallarofa y otras variantes formales parafolla ( $\mathrm{Te} \mathrm{600),} \mathrm{barfolla}(\mathrm{Hu} 403)$, gallarofa (Z 605, Te 400), carafolla ( $\mathrm{Te} 406)$, callorfa (Te 504), pellorfa (Te 304), garfolla (Te 305), carfolla (V 100), se relacionan con el catalán pellerofa 'farfolla', pellofa 'cáscara, corteza' ${ }^{\prime 2}$, el murciano perfolla 'hoja que cubre el fruto del maiz ${ }^{23}$ y con el andaluz oriental perfolla 'farfolla', explicable por influencia murciana ${ }^{24}$, y no aragonesa ${ }^{25}$, ya que en nuestro ámbito lin-

${ }^{21}$ Vid. Azkue, II, 40 (s.v. mits̃ar); II, 173-3 (s.v. pits).

${ }^{22}$ Cfr. $D C V B$, VIII, pp. 405 y 407.

${ }^{23}$ Cfr. J. Garcia Soriano, op. cit., p. 98.

${ }^{24}$ Cfr. M. Alvar, art. cit., p. 28.

25 Cfr. G. Salvador, "Aragonesismos en el andaluz oriental», en Archivo de Filologia Aragonesa, V, 1953, pp. 150-1. 
güistico està variante apenas aparece. El origen de estas voces hay que buscarlo en el cruce de dos étimos latinos: pellis + folia $^{26}$.

La denominación metafórica capota predomina en La Rioja; otras metáforas son más esporádicas: peloca $(\mathrm{Hu} 106,203)$, cascarullo $(\mathrm{Z} 402)$, con un sufijo despectivo por el escaso valor de estas hojas, camisas (Z 202), camochera ( $\mathrm{Z} 300)$, forro ( $\mathrm{Z} 305)$, casco (Z 401).

Formas poco frecuentes son: pernocha $(Z$ 501, 507) surgida por un cruce entre perfolla 'hoja que recubre la mazorca del maíz' y pinocha 'maíz', carriza (Z 600), borriza (Z 603, 604), la voz onomatopéyica coscarana (Te 103), berraza (Te 104), zarrabaina (Te 301), el arabismo corfa (Te 501, 503), que penetra en territorio aragonés a través del valenciano ${ }^{27}$.

\section{MAZORCA}

El término aragonés panolla se registra en la parte oriental del sur de Huesca, sur de Zaragoza y norte de Teruel, coincidiendo con el catalán panolla que se documenta en los pueblos fronterizos que pertenecen a ese dominio lingüístico ${ }^{28}$; la voz castellana panoja se extiende por el sur de Teruel. Es una palabra derivada del latín vulgar panŭcŭla 'mazorca', 'cabellera de una mazorca', diminutivo de pan us 'mazorca de hilo', 'panoja', que se ha mantenido en áreas laterales ${ }^{29}$ en lugar de mazorca, que es el término que se ha generalizado en la lengua común; en nuestro territorio

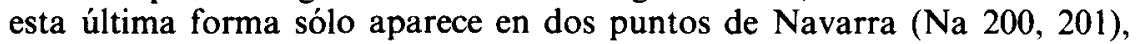
procede de la unión del vocablo árabe māsûra y el castellano horca, ambos con el sentido de 'rueca' y además con el de 'rueca llena de hilo', el valor de 'mazorca' sería secundario y habría surgido por el cierto parecido que existe entre la parte superior del tallo de la espiga del maiz en forma abultada y la 'lanzadera llena de hilo o de lana' ${ }^{30}$.

${ }^{26}$ Cfr. M. Alvar, art. cit., pp. 28-9; vid. además, V. García de Diego, Etimologias Españolas. Madrid, Aguilar, 1964, pp. 648-656, donde señala que para estos términos propios de la zona oriental de la Península hay que pensar en una base con pellis, frente a las formas con $m$ del tipo marojo 'hojas inútiles que sólo se aprovechan para el ganado' (DRAE. s.v.), características de la parte occidental que remontan al latín mala folia.

${ }^{27}$ Cfr. J. Corominas, Diccionari, II, pp. 934-5.

${ }^{28}$ Cfr. $D C V B$, p. 185.

${ }^{29}$ Vid. L. Rodríguez Castellano, Contribución al vocabulario del bable occidental. Oviedo, Instituto de Estudios Asturianos, 1957, p. 216.

${ }_{30} \mathrm{~J}$. Corominas, DCECH, III, pp. 901-3; cfr. además, R. Dozy y W. H. Engelmann, Glossaire des mots espagnols et portugais dérivés de l'arabe (2 ${ }^{\mathrm{ime}}$ ed.). Amsterdam, APA-Oriental Press, 1982, pp. 312-3, señalan que es un híbrido árabe procedente de la contracción de maçora (árabe) + rocca (germánico), con el significado originario de 'rueca', 'huso de rueca', el resto de los valores es figurado. 
La voz pinocha se halla en Huesca, norte y centro de Zaragoza y en la zona oriental de Navarra y La Rioja, el masculino pinocho en $\mathrm{Na} 502$. El DRAE la recoge como aragonesismo con el significado de 'panoja del maíz y del panizo' (s.v.); esta forma surge por confusión con la palabra pinocha, muy extendida en Aragón para designar el 'fruto del pino' ${ }^{31}$, dada la relación formal y semántica que hay entre ambos. El mozarabismo panocha, emparentado con estos términos, no se recoge en ningún punto de nuestro dominio; esto ha de tenerse en cuenta, ya que la aparición de este vocablo en el oriente andaluz no debe de ser de procedencia aragonesa importado a través de Murcia $^{32}$, sino que ha de tratarse de un préstamo directo de las hablas murcianas, donde panocha es la denominación más extendida ${ }^{33}$.

Como hemos señalado anteriormente pinocha es también la designación del 'fruto del pino' en varios pueblos, por lo que en algunos casos se ha producido un sincretismo y la misma forma actualiza los dos valores en $\mathrm{Na}$ 204, 205, 206, 404, 600, Hu 100, 105, 107, 111, 112, 200, 202, 305, 400, 401, 403, 404, 405, Z 101, 200, 201, 402, 600; en otras ocasiones se mantiene la diferenciación a través de la variación de género: pinocho / pinocha ( $\mathrm{Na} 502$ ), pinocha / pinocho (Z 300, 400), que expresan 'mazorca' y 'piña' respectivamente.

Piña se documenta en la parte occidental del centro y sur de Zaragoza, del norte y centro de Teruel y en puntos de La Rioja; ya el DRAE señala como uno de los valores de este término el de 'mazorca del maíz, especialmente cuando carece de farfolla' (s.v. 3." acepción); en dos puntos de la frontera oriental de Huesca $(\mathrm{Hu} 402,408)$ se recoge esta misma forma, pero en este caso es una extensión del catalán occidental pinya, que tiene también este significado.

La designación metafórica de la 'mazorca' con el nombre de piña 'fruto del pino' está motivada por la semejanza formal que existe entre ambas realidades; este hecho ha supuesto, igual que en el apartado anterior, que en muchas localidades se haya convertido en voz polisémica que actualiza los dos valores.

En el centro de Teruel encontramos el vocablo paniza, donde se ha recurrido a un procedimiento morfológico, la variación genérica, para mantener la distinción significativa sin tener que utilizar palabras procedentes de étimos distintos: panizo 'maíz' / paniza 'mazorca' (Te 400, 401, 402, 403, $404,405,600$ ); en dos puntos (Te 308, 406) no se establece esta oposición y el mismo vocablo cubre los dos valores: panizo 'maiz' y 'mazorca'.

Denominaciones metafóricas como cabeza, en puntos de Navarra, por estar en la parte superior de la espiga; capiello en dos puntos de Huesca

$"$ Cfr. M. Alvar, ALEANR, III, mapa 384 y adición.

32 J. Fernández Sevilla, op. cit., p. 123.

${ }^{33}$ Cfr. J. García Soriano, op. cit., p. 95. 
(Hu 102, 104), por estar cubierta por las hojas, la metonimia espiga en puntos de La Rioja, y algún vocablo vasco en el norte de Navarra: artaburu $(\mathrm{Na} 101,102)^{34}$.

\section{Carozo}

En las denominaciones de la 'raspa de la mazorca del maíz' encontramos algunas formas que ya han aparecido anteriormente para designar 'mazorca'. Esto ha supuesto que en algunos casos se haya producido una indistinción léxica entre ambos valores y la misma forma actualiza los significados de 'mazorca' y 'raspa de la mazorca'; esto se explica porque el hablante considera el fruto y la raspa como una única y misma realidad y no ve la necesidad de establecer diferenciación léxica entre ambas: piña ( $\mathrm{Na}$ 203), pinocha ( $\mathrm{Na} \mathrm{400,401,} \mathrm{Lo} \mathrm{600,604,} \mathrm{Hu} \mathrm{108,} \mathrm{111,} \mathrm{202,} \mathrm{203,} \mathrm{204,} \mathrm{400,}$ $406, \mathrm{Z} 100,200,202,305$ ), pinocho ( $\mathrm{Na} 502$ ), panocha (Lo 303), pinochero (Hu 300), penocha (Hu 110). En otras ocasiones se mantiene la distinción a través de procedimientos morfológicos: variación de género: pinocho "carozo' / pinocha 'mazorca' ( $\mathrm{Na} \mathrm{501,} \mathrm{Hu} \mathrm{100,} \mathrm{303,} \mathrm{Z} \mathrm{303,} \mathrm{401,} \mathrm{402);} \mathrm{derivación:}$ pinocha 'mazorca' / pinochera 'carozo' ( $\mathrm{Z}$ 400), paniza 'mazorca' / panicera 'carozo' (Te 400), panolla 'mazorca' / panollizo 'carozo' (Hu 601); o adición de un determinante: pinocha 'mazorca' / pinocha sense grans 'carozo' (Hu 404).

Milloca con el valor de 'raspa de la mazorca' se recoge en $\mathrm{Hu} 112$ y el derivado millocón en $\mathrm{Hu} 105,107$; sólo en $\mathrm{Hu} 105$ se establece una correlación entre el primitivo milloca 'maíz' y el derivado millocón 'raspa de mazorca'; en la actualidad milloca se considera palabra anticuada, mientras que millocón tiene plena vigencia.

En otros casos en los que encontramos formas comunes para ambos valores se mantiene la diferenciación léxica, ya que se emplean étimos distintos para cada uno de ellos: pinocho / espiga (Lo 101), panocha / piña (Lo 103), pinocha / piña (Lo 602), pinocha / capiello (Hu 102), millocón / pinocha ( $\mathrm{Hu} \mathrm{105,} \mathrm{107),} \mathrm{milloca} \mathrm{/} \mathrm{pinocha}(\mathrm{Hu} \mathrm{112),} \mathrm{pinocha} \mathrm{/} \mathrm{piña}(\mathrm{Hu} 402,408, \mathrm{Te}$

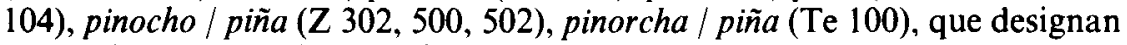
'carozo' y 'mazorca' respectivamente.

Zuro es predominante en la zona oriental, junto con la correspondiente voz catalana suro en los pueblos fronterizos ( $\mathrm{Hu} \mathrm{602,} \mathrm{Z} 606, \mathrm{Te} 202,205$, 207). Es una forma procedente del latin sūber, -èris 'corcho', significado que sigue manteniendo tanto en los pueblos catalanes ${ }^{35}$ como en los

\footnotetext{
${ }^{34}$ Vid. Azkue, I, p. 80.

${ }^{35}$ Cfr. $D C V B, \mathrm{X}, \mathrm{p} .82$
} 
aragoneses $^{36}$. Del aragonés ha pasado al murciano ${ }^{37}$ y a la Andalucía oriental, donde se registra en el norte de Almería, Granada y Jaén ${ }^{38}$.

Cozcorro, palabra que aparece en Navarra es una extensión del vasco koskor 'zuro, mazorca desgranada de maíz', procedente de la onomatopeya kosk 'golpe seco', 'golpe dado con un objeto duro' ${ }^{39}$, de donde derivan también las formas castellano-aragonesas cuscurro y con metátesis corrusco 'mendrugo, cantero de pan'.

El resto de las denominaciones responde a comparaciones metafóricas basadas en el color, la consistencia o su situación en el centro del fruto: corazón, tronco, troncho, raspa (Z 201), raspajo (Te 301), corcho (Te 406), tarugo (Te 600).

\section{CONSIDERACIONES FINALES}

Ante la necesidad de dar nombre a una nueva realidad la lengua utiliza diversos procedimientos. La incorporación de la palabra originaria, maiz, que es la que se generaliza en una gran parte de la península, se acepta en Navarra y La Rioja ${ }^{40}$; en Aragón, por el contrario, no se admite el préstamo y recibe la denominación del antiguo cereal, panizo, que fue suplantado por el maíz después del descubrimiento de América; el mismo desplazamiento se produce en gascón y en el noroeste de Huesca con las formas milloc, milloca, y en el sur de Teruel con la palabra adaza y la correspondiente voz valenciana dacsa, todas ellas designaciones de un cereal de características parecidas.

Para denominar cada una de las partes se adaptan los términos ya existentes en la lengua a través de distintos cambios semánticos: comparaciones metafóricas basadas en la forma (punta, escoba 'flor de maíz', piña 'mazorca'), la posición (capota, camisas, forro 'farfolla', corazón, tronco, raspa 'carozo'), la consistencia (seda, pelos de vieja 'barba de la mazorca'), o bien expresiones metonimicas (espiga, flor 'flor de maíz'); otras veces se trata de restricciones del valor originario (hoja 'farfolla').

En otros casos se emplean procedimientos morfológicos; así la variación de género permite establecer una diferenciación significativa entre 'maíz' (panizo) y 'mazorca' (paniza), o entre 'carozo' (pinocho) y 'mazorca' (pi-

\footnotetext{
${ }^{36} \mathrm{Cfr}$. J. Borao, Diccionario de voces aragonesas (2." ed.). Zaragoza, 1908, p. 335.

Cfr. J. García Soriano, op. cit., pp. 121 y 135 respectivamente.

3* Vid. M. Alvar, ALEA, I, mapa 107.

${ }^{39}$ Cfr. V. García de Diego, Diccionario de voces naturales. Madrid, Aguilar, 1968, pp. 474-5.

40 Cfr. P. García Mouton, art. cit., pp. 122-123.
} 
nocha), y a través de la derivación se distingue entre 'mazorca' (pinocha, paniza, panolla) y 'carozo' (pinochera, panicera, panollizo).

Respecto a la distribución de formas, no hay áreas léxicas bien delimitadas; es evidente el predominio del vocablo autóctono panizo en Aragón frente a maiz en Navarra y La Rioja, pero respecto a los demás términos la división es menos clara; por ejemplo, hay preferencia por los vocablos flor 'flor de maíz', hoja 'farfolla', pinocha 'mazorca' en la zona norte de este ámbito lingüístico, mientras que los términos correspondientes espigón, pallarofa y derivados, piña, para designar cada uno de esos valores, se hallan en el sur; capota 'farfolla' es una metáfora específica de La Rioja y cozcorro se limita a Navarra, ya que es una palabra procedente del vasco. 
1. Maíz

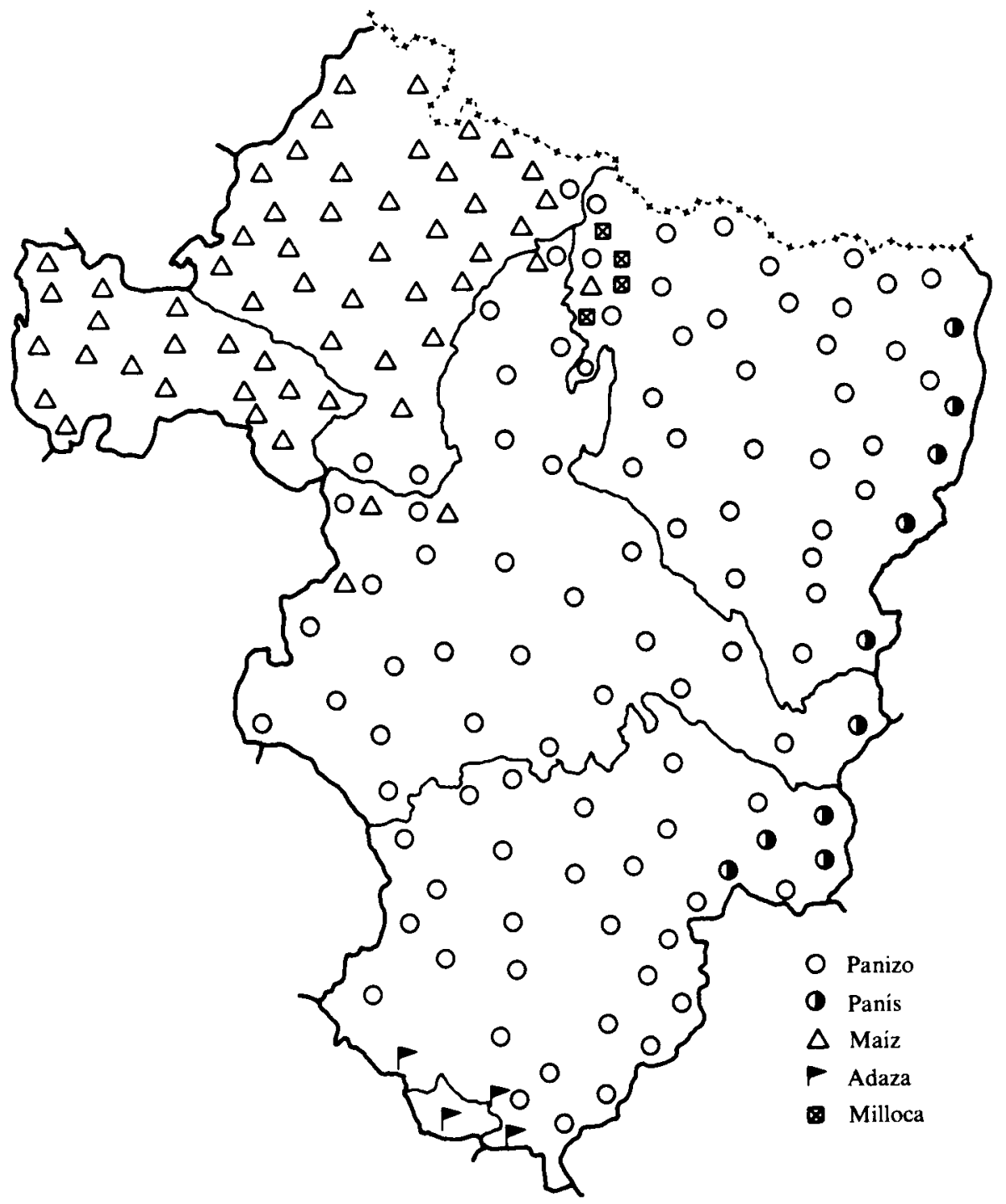


2. FLor del Maíz

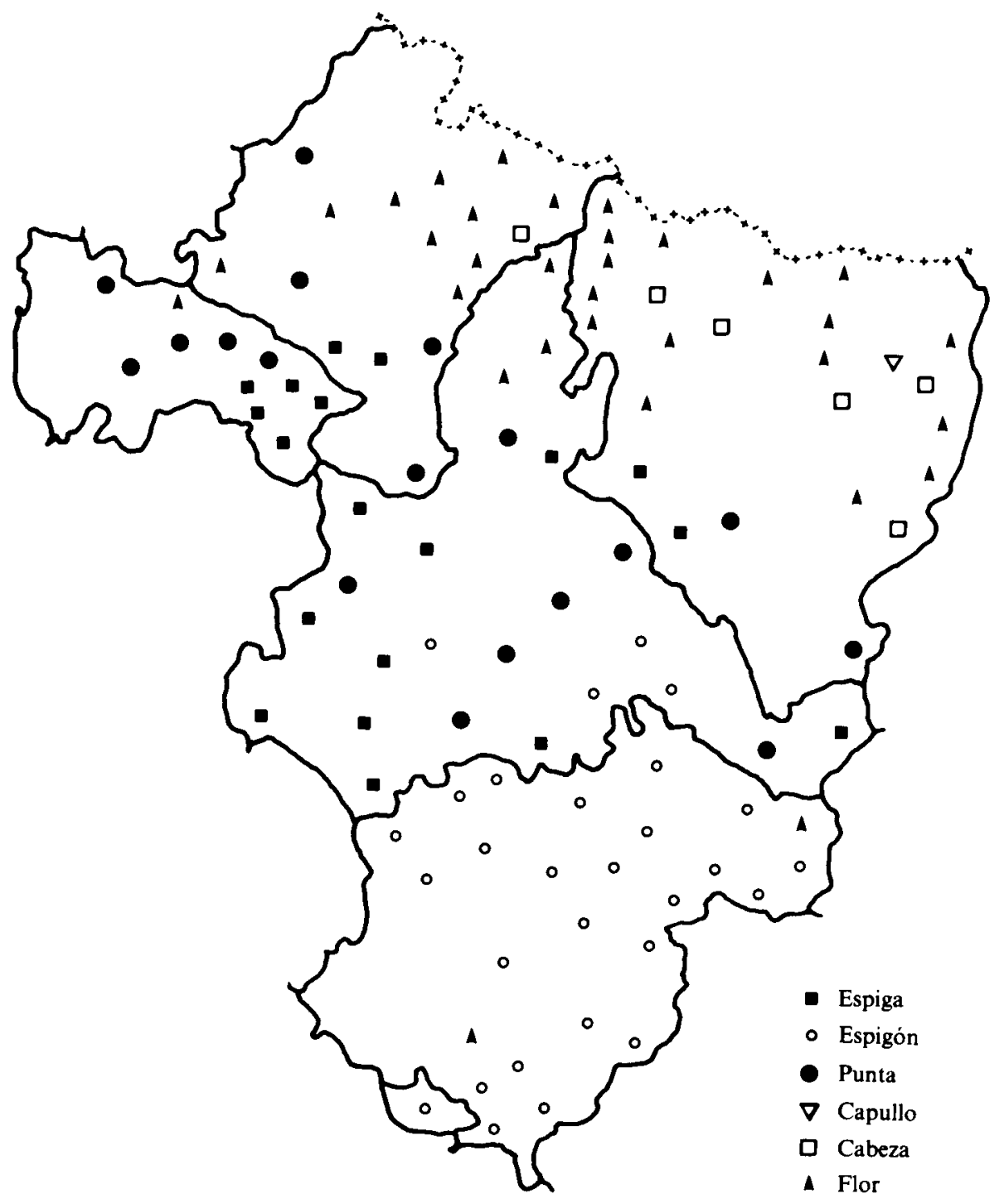


3. Barba de la Mazorca

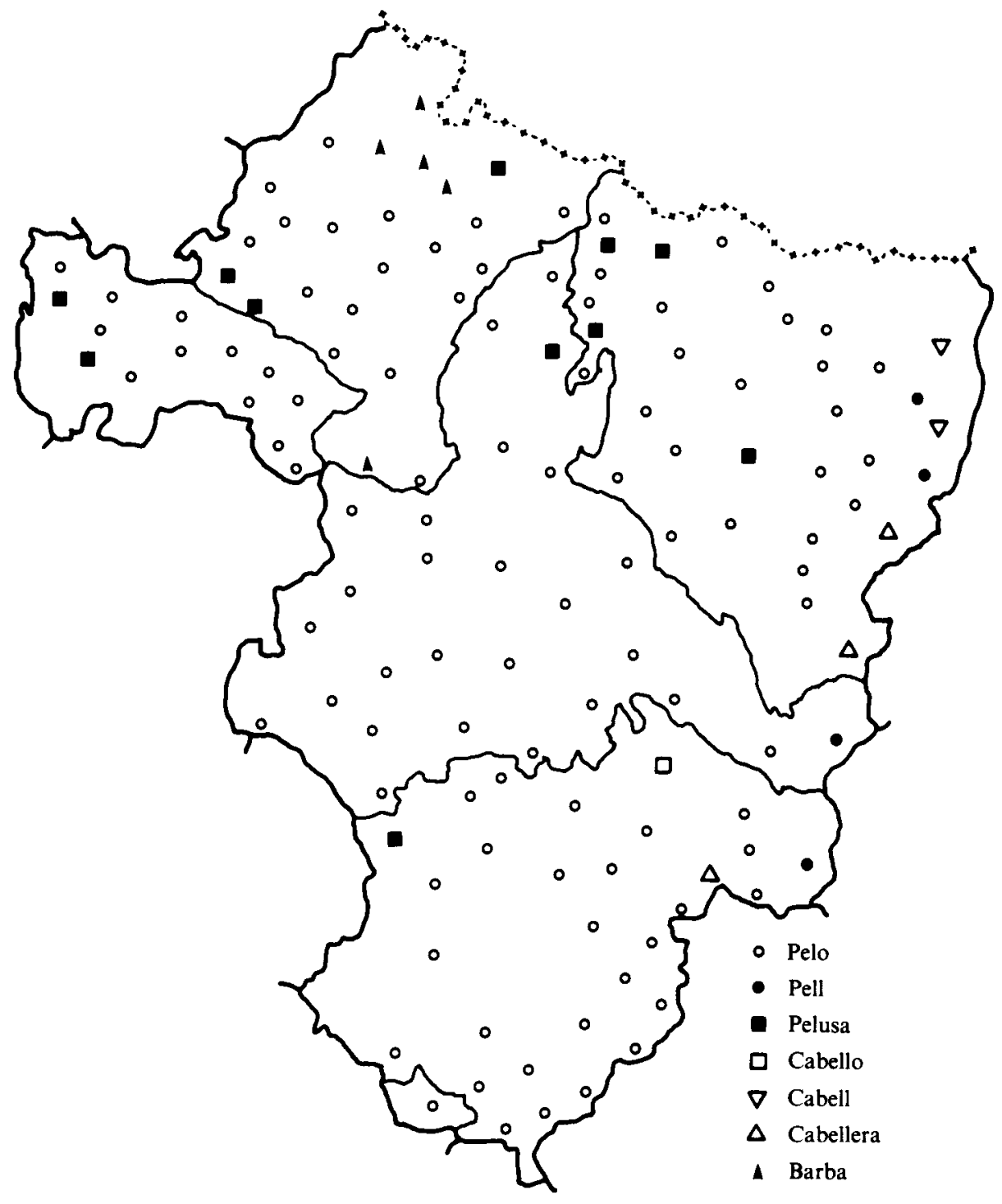




\section{Farfolla}

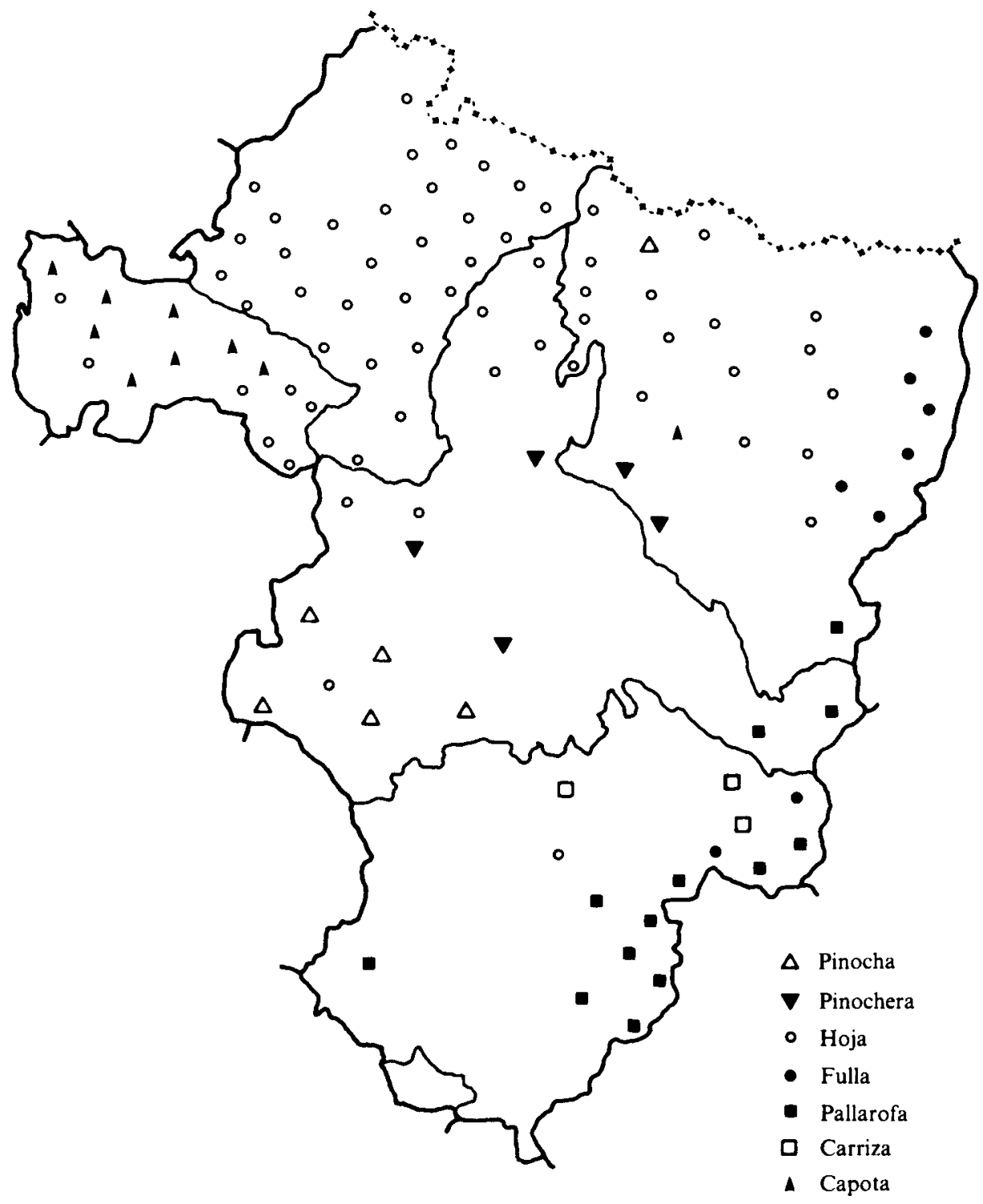




\section{Carozo}

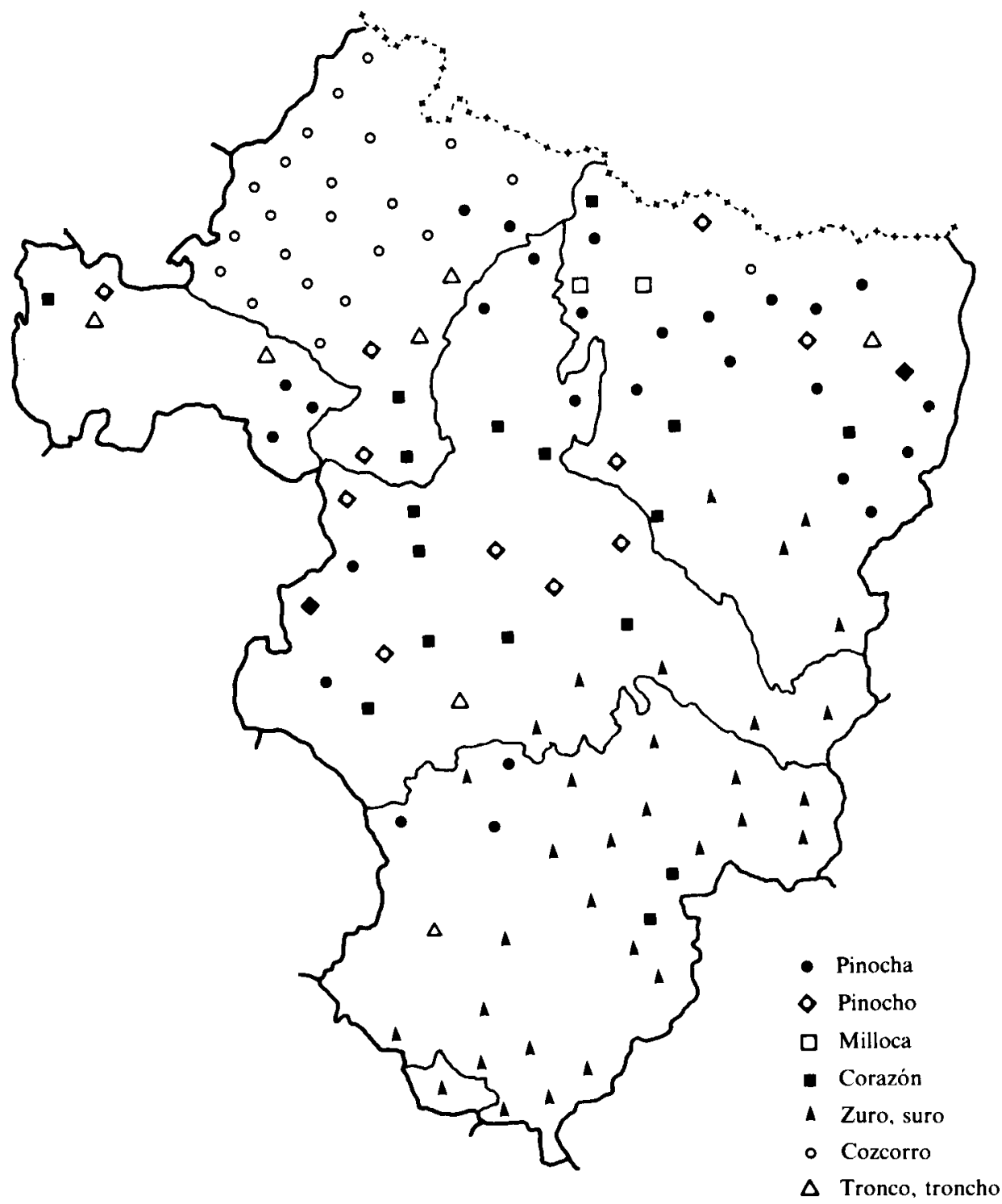

